\title{
On the role of competing word units in visual word recognition: The neighborhood frequency effect
}

\author{
JONATHAN GRAINGER, J. KEVIN O'REGAN, ARTHUR M. JACOBS, and JUAN SEGUI \\ René Descartes University, Paris, France \\ and C.N.R.S., Paris, France
}

\begin{abstract}
Current models of word recognition generally assume that word units orthographically similar to a stimulus word are involved in the visual recognition of this word. We refer to this set of orthographically similar words as an orthographic neighborhood. Two experiments are presented that investigate the ways in which the composition of this neighborhood can affect word recognition. The data indicate that the presence in the neighborhood of at least one unit of higher frequency than the stimulus word itself results in interference in stimulus word processing. Lexical decision latencies (Experiment 1) and gaze durations (Experiment 2) to words with one neighbor of higher frequency were significantly longer than to words without a more frequent neighbor. This neighborhood frequency effect is discussed in terms of the different types of candidate selection process postulated by contemporary models of visual word recognition.
\end{abstract}

Most current models of visual word recognition assume that the recognition process may be subdivided into at least three phases, which are referred to here as candidate generation, candidate selection, and conscious identification. In the candidate generation phase, the word input contacts a number of orthographically similar lexical representations in memory. Using information from the continued sensory analysis and any contextual information available, one of these candidates is selected for conscious identification. This general conception of the word recognition process adopts various precise forms in models such as Becker's (1976) verification model; Forster's (1976) search model; McClelland and Rumelhart's (1981) interactive-activation model; Morton's (1970) logogen model; Norris's (1986) checking model; and Paap, Newsome, McDonald, and Schvaneveldt's (1982) activation-verification model. These different models place different constraints on the individual operation of these subprocesses and the ways they interact, but the models all assume that both sublexical and wholeword units (other than the stimulus word itself) are involved in visual word recognition.

Research concerned with the role of whole-word units in word recognition has concentrated largely on establishing effects due to various parameters of the stimulus word itself (e.g., printed frequency, repetition, orthographic and

The authors would like to thank Madeleine Leveillé for programming the computer search of the four-letter word corpus, and Françoise Vitu for help in the running and data analysis of the eye movement study. We would also like to thank Paul Luce, Leonard Katz, and Lester Krueger for their comments on an earlier version of this article. This research was partly supported by postdoctoral fellowships from the Fyssen Foundation, Paris, awarded to the first and third authors. Reprint requests should be addressed to Jonathan Grainger, Laboratoire de Psychologie Expérimentale, 28 rue Serpente, 75006 Paris, France. phonological regularity). Most of the research regarding lexical units other than the stimulus word has examined how the prior presentation of another word can influence recognition performance (semantic and formal priming; see, e.g., Humphreys, Evett, Quinlan, \& Besner, 1987; Neely, 1977). However, one area of research that has been largely neglected until now is how the lexical candidates generated by the stimulus word affect the recognition of this word. We address this particular field of investigation in the present article.

Much of the prior research in this area has examined the influence of the size of the hypothetical set of lexical candidates on word recognition performance. This hypothetical set is referred to as a word's orthographic neighborhood, and one possible measure of its size is the $N$ measure described by Coltheart, Davelaar, Jonasson, and Besner (1977). $N$ is defined as the number of different words in a given language that can be generated by changing only one letter in the stimulus word to another letter, preserving letter positions. The results at present indicate that in a lexical decision task there is no influence of $N$ on latencies to words, but that nonwords with higher $N$ values are rejected more slowly (Coltheart et al., 1977; Gunther \& Greese, 1985; Scheerer, 1987). On the other hand, there is some evidence for an $N$ effect on word naming latencies, in which words with larger neighborhoods are named more rapidly (Gunther \& Greese, 1985; Scheerer, 1987); however, this result may simply be due to the fact that words with more neighbors have more frequent spelling-to-sound correspondences. Brown (1987) recently demonstrated that this factor does indeed influence naming performance. The same type of criticism can be leveled at the observed absence of $N$ effects in lexical decision latencies to words. Because $N$ is typically confounded with bigram frequency, increasing ortho- 
graphic neighborhood size may indeed slow recognition latencies, but this effect may be cancelled by a facilitatory effect of higher bigram frequency. It is therefore necessary to test for $N$ effects while maintaining bigram frequency constant.

However, the important factor here may not be the size of the neighborhood $(N)$, but rather the frequency of these neighbors relative to that of the stimulus word. This makes sense when one considers that many contemporary models of word recognition predict effects due to the frequency of the elements in the candidate set and not to the total size of this set. Thus, for example, in serial search type models (Becker, 1976; Forster, 1976; Paap et al., 1982), a self-terminating frequency-ordered search is performed on the candidate entries, so the presence of higher frequency candidates should slow down the identification process. In interactive-activation type models (McClelland \& Rumelhart, 1981), on the other hand, intralevel inhibition operating between activated entries will be a function of the frequency of these entries. Only an exhaustive serial search model would predict a pure $N$ effect for words, and to our knowledge no such model exists for visual word recognition, although such a model may be quite appropriate for nonword recognition.

Some indications do exist in the literature that the frequency of the neighbors relative to stimulus word frequency does indeed affect word recognition performance. Savin (1963) found that short low-frequency words such as tat had high auditory thresholds and generated more errors than did high-frequency words (cat given 9 out of 12 times for tat) at subthreshold presentations. He suggested that this may be due not simply to their low printed frequency, but to a response bias induced by the existence of a similar high-frequency word. Havens and Foote (1963) found essentially the same effect for visual threshold durations. Their results indicate that threshold values do not vary significantly as a function of word frequency, but are primarily a function of the ability or inability of the stimuli to evoke high-frequency competitive responses.

More recently, Chambers (1979) investigated interference effects in the recognition of words that are orthographically similar to a more frequent word in two different ways: a word that differs by a single letter (e.g., collar from dollar, referred to as substitution neighbors), and a word that differs in the order of two adjacent letters (e.g., bale from able, referred to as transposition neighbors). Chambers found interference effects for only the latter type of neighbor; that is, longer lexical decision latencies relative to controls were observed for bale-type words and not for collar-type words. This result is problematic for models that assume position-specific letter activation in the recognition of words (McClelland \& Rumelhart, 1981; Paap, et al., 1982). In fact, such models would predict exactly the opposite, that is, effects for collar-type words and not for bale-type words. There are, however, a number of points on which these experiments can be criticized. First, the control words were matched for printed frequency, but not for experiential familiarity (subjective ratings of words on a familiarity scale). On the basis of the work of Gernsbacher (1984) and Gordon (1985), it is now known that low printed frequency words can vary enormously in familiarity and that experiential familiarity is a better predictor of lexical decision latencies. Second, all the collar-type words were five to seven letters long, whereas all but two of the bale-type words that gave consistent interference effects were short words (three to five letters). We therefore decided to test for an interference effect in short words (four letters) that have more frequent substitution neighbors (which we refer to using the more general term orthographic neighbors).

\section{EXPERIMENT 1: LEXICAL DECISION}

This experiment was designed to study three possible effects in lexical decision latencies to words: an effect of the presence of orthographic neighbors while controlling for bigram frequency, an effect of the presence of an element of higher frequency than the stimulus word in the orthographic neighborhood, and a cumulative effect of the number of higher frequency elements in the neighborhood.

\section{Method}

Stimuli. The orthographic neighbors of all four-letter French words were generated by computer search. These neighbors are defined as all other French four-letter words that share three letters in the same position. Using printed frequency measures (Trésor de la Langue Française, 1971), these words were grouped into four categories: (1) words with no orthographic neighbors; (2) words with at least one orthographic neighbor, none of which is of higher frequency than the word itself; (3) words with at least one orthographic neighbor, only one of which is of higher frequency than the word itself; and (4) words with more than one orthographic neighbor of higher frequency. Because experiential familiarity is now considered a better predictor of word recognition performance than is printed frequency (Gernsbacher, 1984; Gordon, 1985), these words were rated by 50 psychology students on a 7-point familiarity scale $(1=$ very unfamiliar, $7=$ very familiar $)$, and the mean familiarity rating was calculated for each word. For the final selection of the experimental stimuli, the four item categories were equated for average familiarity rating and printed frequency. For each category, the mean frequency was 30 per million with maximum upper and lower frequency values of 80 and 5 per million, respectively, and the mean familiarity rating was 4.2 with maximum upper and lower values of 5.8 and 3.2 , respectively. The four categories were also matched as far as possible for positional bigram frequency, which was calculated using a token count of the four-letter word corpus. However, the words with several more frequent neighbors had necessarily higher bigram frequencies than the other categories. Examples of the final four categories are given in Table 1, with the mean bigram frequency and orthographic neighborhood for each category. Ten items were selected for each category, resulting in a total of $\mathbf{4 0}$ stimulus words. Twenty other noncritical four-letter words were added as filler items. Finally, 60 four-letter orthographically legal, pronounceable pseudowords were constructed for the lexical decision task.

Procedure. Stimuli were presented individually on a Hewlett Packard cathode ray scope controlled by an Apple IIe computer interfaced with a Hewlett Packard 1351A graphics generator. A central fixation point was presented for $500 \mathrm{msec}$, followed by a 500 msec delay, and then the stimulus item was presented centered on the fixation point. The stimulus remained on the screen until the subject pressed one of two response keys to indicate whether the 
Table 1

Description of the Item Categories

\begin{tabular}{|c|c|c|c|c|}
\hline & \multicolumn{4}{|c|}{ Item Category } \\
\hline & 1 & 2 & 3 & 4 \\
\hline $\begin{array}{l}\text { Example } \\
\text { Orthographic } \\
\text { Neighborhood }\end{array}$ & $\begin{array}{c}\text { BREF } \\
-\end{array}$ & $\begin{array}{l}\text { JUPE } \\
\text { dupe } \\
\text { jute } \\
\text { juge }\end{array}$ & $\begin{array}{l}\text { NERF } \\
\text { neuf* } \\
\text { cerf } \\
\text { serf }\end{array}$ & $\begin{array}{l}\text { FOIN } \\
\text { coin* } \\
\text { loin* } \\
\text { fois* } \\
\text { foie } \\
\text { soin }\end{array}$ \\
\hline $\begin{array}{l}\text { Average Number } \\
\text { of Neighbors } \\
\text { Mean Positional }\end{array}$ & 0 & 2.2 & 2.6 & 7.9 \\
\hline Bigram Frequency & 7.0 & 7.0 & 6.3 & 16.3 \\
\hline
\end{tabular}

*Orthographic neighbors that have higher frequencies than the corresponding example stimulus word.

stimulus was a word (using the index finger of the preferred hand) or not a word (using the index finger of the nonpreferred hand). The subjects were instructed to respond as rapidly as possible. Each subject was given a list of 40 practice trials containing 20 fourletter words and 20 four-letter pseudowords, none of which appeared in the experimental trials. Stimulus presentation order was randomized for each subject.

Subjects. Twenty third-year psychology students at René Descartes University, Paris, participated in the experiment for course credit. All were native speakers of French.

\section{Results}

The means of the lexical decision latencies and percentages of errors by subjects and item category are given in Table 2.

An analysis of variance was performed on the reaction time data, and planned comparisons were carried out for the relevant category pairs. The $F$ values are given by subject $\left(F_{1}\right)$ and item $\left(F_{2}\right)$. The 6-msec difference between Categories 1 and 2 (effect of the presence of an orthographic neighborhood) is not significant $\left(F_{1}<1\right.$, $F_{2}<1$ ). The 47 -msec difference between Categories 2 and 3 (effect of the presence of a more frequent neighbor) is highly significant $\left[F_{1}(1,19)=25.77, p<.001\right.$; $\left.F_{2}(1,18)=7.21, p<.025\right]$, as is the 55 -msec difference between Categories 2 and $4\left[F_{1}(1,19)=26.91\right.$, $\left.p<.001 ; F_{2}(1,18)=4.63, p<.05\right]$. The 8-msec difference between Categories 3 and 4 (cumulative effect of the number of higher frequency neighbors) is not significant $\left(F_{1}<1 ; F_{2}<1\right)$.

An analysis of the error data showed basically the same trends as those observed in the reaction time data. The difference between Categories 1 and 2 is significant by

Table 2

Experiment 1: Mean Lexical Decision Response Times (in msec) and Percentages of Errors (\%E)

\begin{tabular}{cccl}
\hline \multirow{2}{*}{$\begin{array}{c}\text { Item } \\
\text { Categories }\end{array}$} & \multicolumn{2}{c}{ Response Times } \\
\cline { 2 - 3 } & $M$ & $S E$ & $\% \mathrm{E}$ \\
\hline 1 & 602 & 12.8 & 4.5 \\
2 & 596 & 20.7 & 0 \\
3 & 643 & 17.6 & 5.0 \\
4 & 651 & 20.6 & 5.0 \\
Pseudowords & 747 & 28.2 & 8.9 \\
\hline
\end{tabular}

subject $\left[F_{1}(1,19)=11.07, p<.01\right]$ but not by item $\left[F_{2}(1,18)=2.71\right]$. However, only one particular item in Category 1 gave a very high error rate (rapt, 33\%). Removing this item reduces the error rate for Category 1 to $2.3 \%$. Categories 3 and 4 produced a significantly greater number of errors than Category 2 , both in the subject and the item analysis [Categories 2 and $3: F_{1}(1,19)$ $=6.33, p<.025 ; F_{2}(1,18)=8.35, p<.01 ;$ Categories 2 and $4: F_{1}(1,19)=10.56, p<.01 ; F_{2}(1,18)$ $=10.83, p<.01]$. There was no difference in the error rates to Category 3 and Category 4 words $\left(F_{1}<1\right.$; $\left.F_{2}<1\right)$.

\section{Discussion}

Experiment 1 provided clear-cut data on two of the three effects that were discussed at the end of the introduction. First, the absence of a significant increase in reaction times from Category 1 to Category 2 suggests that neighborhood size per se does not affect lexical decision performance. This confirms the previous work on $N$ effects (Coltheart et al., 1977) while controlling for the possible counteractive effects of bigram frequency. Second, the significant increase in reaction times and error rate from Category 2 to Categories 3 and 4 demonstrates a strong effect of the presence of at least one element in the orthographic neighborhood that is of higher frequency than the stimulus word itself. Finally, the fact that we failed to observe a significant increase in reaction times or error rate from Category 3 to Category 4 suggests that increasing the number of higher frequency neighbors does not further increase processing difficulty. Apparently, the presence of at least one neighbor of higher frequency than the stimulus word itself produces longer lexical decision latencies. We cannot, however, firmly conclude that increasing the number of higher frequency neighbors does not increase interference. As was noted in the description of the stimuli, Category 4 words have higher bigram frequencies than Category 3 words, and thus any extra interference could have been canceled by the facilitatory effects of bigram frequency.

One other possible confounding factor is the position of the letter change between the stimulus word and its orthographic neighbors. It might be that neighborhood interference effects appear only when the neighbors share the initial part of the stimulus word (any system with leftto-right oriented processing would predict this). Within the three categories of words that had orthographic neighbors, however, the numbers of word-initial and wordterminal changes were distributed evenly across these categories. Thus, the observed differences in lexical decision latencies between the categories cannot be attributed to this factor. It was, however, possible to split Category 3 words into two reasonably matched groups of items: words whose higher frequency neighbors differed by the initial letter, and words whose higher frequency neighbors differed by either the third or fourth letter. The mean lexical decision latencies for these two groups of words were $636 \mathrm{msec}$ and $643 \mathrm{msec}$, respectively. This post hoc 
analysis, therefore, suggests that the neighborhood frequency effect does not depend on the position of letter change between the stimulus word and its higher frequency neighbor.

One final difficulty in interpreting the neighborhood frequency effect observed in Experiment 1 concerns the possible loci of this effect. This problem arises because effects observed with the lexical decision task cannot be unequivocally assigned to processes operating during word recognition. Balota and Chumbley (1984) suggested that the decisional component of the lexical decision task may be responsible for a major part of the effects observed with this task. Thus, it could be argued that the presence of a higher frequency neighbor is not interfering with recognition processes, but rather is influencing a decision criterion that the subjects use to perform the lexical decision task. This interpretation is analogous to the response bias interpretation suggested by Savin (1963). For this reason, we decided to test for the presence of a neighborhood frequency effect using a technique that provides a more direct measure of recognition latencies.

One argument that Balota and Chumbley (1984) used to stress the role of the decision stage in lexical decision is that latencies in this task are typically twice as long (500-600 msec/word) as normal reading rates (300 $\mathrm{msec} /$ word). Experiment 2 therefore used a task in which subjects simply had to read test words before performing a secondary semantic comparison task. The dependent variable was eye gaze duration on the test words.

\section{EXPERIMENT 2: EYE MOVEMENT STUDY}

Experiment 2 was run to see if the neighborhood frequency effect observed in Experiment 1 using the lexical decision task would also be observed at the level of eye gaze durations. There are several reasons for using this measure of word recognition time to consolidate the results obtained with the lexical decision task. First, at $400 \mathrm{msec}$, gaze durations for isolated words are about 200 msec shorter than lexical decision times (see O'Regan \& Lévy-Schoen, 1987; O'Regan, Pynte, Lévy-Schoen, \& Brugaillère, 1984), so there is less chance that they reflect the type of decisional processes that may be operating in lexical decisions. Second, in the type of task used in Experiment 2 (semantic comparison), the subject only has to read and understand the word before comparing it with another word. This task probably provides a better reflection of normal reading, because the subject is trying to understand the word and not trying to check whether he or she knows it. Finally, the absence of pseudowords in this task eliminates all possible interferences from uncontrolled characteristics of such stimuli that are known to affect lexical decision performance.

There is evidence that word frequency affects total gaze duration in a word comparison task similar to the one used in the present experiment (Holmes \& O'Regan, 1987; O'Regan \& Lévy-Schoen, 1987). These data suggest that the total duration of eye fixations on a word reflects, to a certain extent, the lexical processing performed on this word. It is therefore reasonable to think that if the neighborhood frequency effect observed in Experiment 1 is indeed the result of certain mechanisms operating during word recognition, then one should observe this effect in the gaze duration data.

\section{Method}

Stimuli. The test words were the same as those used in Experiment 1 . No pseudowords were necessary in this experiment. For each test word, another word was chosen that was either semantically related (for half the test words) or semantically unrelated to the test word. The comparison words were generated for the purposes of the semantic comparison task.

Apparatus and Procedure. The subject wore a spectacle-mounted device that recorded eye movements photoelectrically using the sceral reflection technique (Barbin, 1982; O'Regan, Lévy-Schoen, \& Jacobs, 1983). The subject sat $60 \mathrm{~cm}$ in front of a VELEC VS video monitor with a fast $\mathrm{P} 4$ phosphor that decayed to $10 \%$ in $0.024 \mathrm{msec}$. His/her head was stabilized by a chin/forehead rest. Before the experiment began, there was a calibration phase in which the subject fixated calibration marks and the experimenter adjusted the apparatus so that the computer knew where the subject was looking. High accuracy was required only in the immediate vicinity of the location where the test word was to appear. For each trial, two vertically aligned horizontal line segments appeared above and below the position where the test words occurred. The subject fixated the gap between the lines. A cursor moved on the screen indicating where the computer thought the subject was looking. The offset between where the cursor was and where the subject was looking was due to calibration error and could be corrected by the subject's making slight adjustments of head position. When the computer detected the continual presence of the cursor aligned between the fixation lines for $100 \mathrm{msec}$, it assumed that fixation was occurring at the fixation gap and caused the cursor to disappear and the stimulus pair to appear. The stimulus pair consisted of a test word and a comparison word, only one of which was available at a time. The other was pattern masked. First, the center of the test word was positioned at the location of the fixation gap, and the masked comparison word was positioned one character space to the right of the end of the test word. The subject's task was to read the test word, shift his/her gaze to the comparison word, read it, and indicate by pressing one of two response buttons whether or not the two words were semantically related. As soon as the subject shifted his/her gaze from the test word to the comparison word, the pattern mask was removed from the comparison word and was placed on the test word to minimize further processing of this word. Both words disappeared when the subject pressed one of the two response buttons. The order of presentation was randomized, with a different order for each subject.

Subjects. Twenty third-year psychology students at René Descartes University, Paris, participated in the experiment for course credit. All were native speakers of French and had not taken part in the previous experiment.

\section{Results}

The means of the gaze durations (defined as the total time subjects spent fixating the test word before moving their eyes to the comparison word) by subjects and item category are given in Table 3.

An analysis of variance was performed on the data, and planned comparisons were carried out for the relevant category pairs, as in Experiment 1 . The 13-msec difference between Categories 1 and 2 (effect of the presence 
Table 3

Experiment 2: Mean Eye Fixation Duration (in msec) and Standard Errors

\begin{tabular}{lllcc}
\hline & \multicolumn{5}{c}{ Item Category } \\
\cline { 2 - 5 } & 1 & 2 & 3 & 4 \\
\hline Gaze Duration & 392 & 405 & 457 & 421 \\
$S E$ & 17.3 & 17.3 & 24.9 & 24.8 \\
\hline
\end{tabular}

of a neighborhood) is not significant, neither by subject $\left[F_{1}(1,19)=1.19\right]$ nor by item $\left(F_{2}<1\right)$. The 52 -msec difference between Categories 2 and 3 (effect of the presence of a more frequent neighbor) is significant by subject $\left[F_{1}(1,19)=25.77, p<.001\right]$ and by item $\left[F_{2}(1,18)=7.21, p<.025\right]$. However, the $16-\mathrm{msec}$ difference between Categories 2 and 4 is not significant by subject $\left[F_{1}(1,19)=1.41\right]$ or by item $\left[F_{2}(1,18)=\right.$ 2.14]. The 36-msec difference between Categories 3 and 4 in the wrong direction (cumulative effect of higher frequency neighbors) is not significant $\left[F_{1}(1,19)=2.31\right.$, $\left.F_{2}<1\right]$.

\section{Discussion}

The results of Experiment 2 generally reflect the same trends observed in Experiment 1 . The principal result of Experiment $1-$ a significant increase in lexical decision latencies from Category 2 to Category 3 -is strongly supported by the data of Experiment 2 . Thus the presence of one orthographic neighbor of higher frequency than the stimulus word itself not only induces longer lexical decision times, but also incurs longer gaze durations on the stimulus word. The fact that we observe a significant effect with the gaze duration data rules out any interpretation of the effect as being due to postrecognition decisional processes operating in the lexical decision task.

However, whereas we observed a significant increase in lexical decision latencies from Category 2 to Category 4 in Experiment 1, the increase in fixation duration was not significant in Experiment 2. In fact, the major difference in the results of these two experiments is the slight rise in reaction times from Category 3 to Category 4 in Experiment 1 and the drop in fixation durations in Experiment 2 . It would appear that the greater bigram frequency of the items of Category 4 facilitated their processing in Experiment 2. Thus the absence of a cumulative effect of higher frequency neighbors in both experiments may well be due to a canceling of any additional interference by the facilitatory effects of bigram frequency. However, an analysis of covariance conducted on the item means showed that covarying bigram frequency did not affect the insignificant differences observed between Categories 3 and 4 , either in terms of lexical decision latencies or in terms of gaze duration. However, this analysis can be considered only indicatory, because homogeneity of covariance did not obtain across these two categories. The present results do not therefore allow us to conclude as to the presence or absence of a cumulative effect of number of higher frequency neighbors. Research being carried out at present, in which number of higher frequency neighbors has been varied independently of bigram frequency, should provide a clearer answer to this question.

A post hoc analysis of Category 3 words, in terms of the position of letter change between the higher frequency neighbor and the stimulus word, revealed no difference in gaze durations. The item means for the words whose higher frequency neighbor differed by the initial letter and for the words whose higher frequency neighbor differed by the third or fourth letter were $439 \mathrm{msec}$ and $440 \mathrm{msec}$, respectively. This therefore consolidates the analysis performed on the lexical decision data and suggests that the position of letter change does not influence the size of the neighborhood frequency effect in four-letter words.

\section{GENERAL DISCUSSION}

When one controls for printed frequency, experiential familiarity, and positional bigram frequency, the fact that a given word possesses an orthographic neighbor of higher frequency than itself increases the duration of lexical processing on that word. This effect, which we have termed the neighborhood frequency effect, is of major relevance to current models of visual word recognition. In particular, most of these models correctly predict the existence of such a frequency effect and the absence of a pure $N$ effect. Only Morton's (1970) logogen model incorrectly predicts the absence of any kind of neighborhood effect; according to this model, the rise in activation of a given logogen is totally independent of the activation levels of all other logogens. Although the present results do not allow us, and were not intended, to distinguish among the remaining models, further research examining the various factors that determine the magnitude of the neighborhood frequency effect could eventually provide this possibility.

Some similar experiments have recently been carried out with bilingual subjects (Grainger, 1989). The results of these experiments indicate that lexical decision latencies to the words of one of the bilingual's languages are influenced by the orthographic neighborhood of these words in the other language. These results support Grainger and Beauvillain's (1987) suggestion that a given orthographic pattern can simultaneously activate word units in both of the bilingual's languages. Further evidence for this position is provided by Beauvillain and Grainger (1987), who demonstrated that both meanings of interlexical homographs such as coin (which means "corner" in French) were initially accessed independently of the language context in which these words were presented. Contextual information could apparently be used later in the selection phase to isolate the appropriate meaning. The precise nature of these selection processes, however, remains a major question for research in word recognition, and one for which very different solutions have been proposed.

Let us now briefly consider how the neighborhood frequency effect observed in the present experiments may 
help determine which type of model provides the most accurate description of these selection processes. Two main mechanisms can be invoked to explain the neighborhood frequency effect: an intralevel inhibitory mechanism operating between representational nodes for words, as in the interactive-activation model (McClelland \& Rumelhart, 1981), and a frequency-ordered serial search operating on candidate entries, as in serial search models (Becker, 1976; Forster, 1976; Norris, 1986; Paap et al., 1982).

In McClelland and Rumelhart's (1981) interactiveactivation model, the representational nodes of words that share physical features with the stimulus word are activated. Since activation arises as a function of physical similarity, and higher frequency words have a higher resting level activation than do low-frequency words, the nodes of orthographic neighbors of higher frequency than the stimulus word could have higher activation levels than the stimulus word representation in initial stages of processing. In this case the stimulus word representation will be initially inhibited, and the total inhibition should be a function not only of the number of higher frequency neighbors, but also of the quantitative difference in frequency and physical similarity between the neighbors and the stimulus word. In serial search models, there is a frequency-ordered search of the set of candidates generated by an initial sensory analysis (and by contextual information in Becker's, 1976, and Paap et al.'s, 1982 , models). The main prediction of this class of models is that the number of higher frequency orthographic neighbors (in the absence of semantic context) should determine recognition latencies. Each element in the candidate set is submitted to a verification process that checks it against available sensory information. The highest frequency elements are checked first, and as each verification cycle is of a fixed duration, the time required to reach the candidate that conforms to the sensory input is a function of the number of other candidates of higher frequency. On the other hand, quantitative differences in frequency between the stimulus word and its higher frequency neighbors should not affect processing. It is sufficient for the neighbor to be of higher frequency, no matter how much higher. It is therefore clear that these two mechanisms make distinct predictions concerning the factors that should determine the magnitude of the neighborhood frequency effect.

One other important area of research in word recognition in which the neighborhood frequency effect should prove useful concerns the composition of the set of lexical candidates contacted by a given stimulus word. By examining fluctuations in the magnitude of the neighborhood frequency effect with various types of neighbors (substitution neighbors with word-initial change, substitution neighbors with word-terminal change, transposition neighbors, neighbors with one letter added or subtracted, etc.), it might eventually be possible to define the parameters that determine candidate set composition. Thus, for example, concerning the relative importance of word-initial and word-terminal information in word recog- nition, it will be important to compare the magnitude of neighborhood frequency effects as a function of the letter position at which the stimulus word and its higher frequency neighbor differ. An analysis of the item means in the present experiments comparing words with higher frequency neighbors sharing word-initial information and words with higher frequency neighbors sharing wordterminal information indicated no difference in either lexical decision latencies or gaze duration. Experiments are currently being run that directly manipulate this factor and compare the effects in short (four-letter) and longer (sixletter) words. Also, concerning the debate over letter position specificity, it will be interesting to see whether words with a more frequent transposition neighbor (without a more frequent substitution neighbor) will be affected to the same extent as the words with more frequent substitution neighbors in the present experiments.

We have indicated two fundamental areas of research in word recognition where the neighborhood frequency effect observed in the present experiments should prove to be a useful experimental tool for testing the different descriptions of the underlying processes provided by contemporary models. These models must now be constrained in order to generate specific experimental predictions concerning the neighborhood frequency effect relative to quantitative or qualitative descriptions of the neighborhood.

\section{REFERENCES}

Balota, D. A., \& Chumbley, J. I. (1984). Are lexical decisions a good measure of lexical access? The role of word frequency in the neglected decision stage. Journal of Experimental Psychology: Human Perception \& Performance, 10, 340-357.

BARBIN, Y. (1982). "Cybermétrope": Un système analogique de traitement du signal pour l'étude en temps réel des mouvements oculaires horizontaux dans des contextes d'éclairement ambiants variés. Paris: University of Paris. D.E.A. Eléctronique Instrumentation.

Beauvillain, C. \& Grainger, J. (1987). Accessing interlexical homographs: Some limits of a language-selective access. Journal of Memory \& Language, 26, 658-672.

BECKER, C. A. (1976). Allocation of attention during visual word recognition. Joumal of Experimental Psychology: Human Perception \& Performance, 2, 555-566.

Brown, G. D. A. (1987). Resolving inconsistency: A computational model of word naming. Journal of Memory \& Language, 26, 1-23.

Chambers, S. M. (1979). Letter and order information in lexical access. Journal of Verbal Learning \& Verbal Behavior, 18, 225-241.

Coltheart, M., Davelaar, E., Jonasson, J. T., \& Besner, D. (1977). Access to the internal lexicon. In S. Dornic (Ed.), Attention and performance VI (pp. 535-555). New York: Academic Press.

Forster, K. I. (1976). Accessing the mental lexicon. In R. J. Wales \& E. W. Walker (Eds.), New approaches to language mechanisms (pp. 257-287). Amsterdam: North-Holland.

Gernsbacher, M. A. (1984). Resolving 20 years of inconsistent interactions between lexical familiarity and orthography, concreteness, and polysemy. Journal of Experimental Psychology: General, 113, 256-281.

GorDON, B. (1985). Subjective frequency and the lexical decision latency function: Implications for mechanisms of lexical access. Jour nal of Memory \& Language, 24, 631-645.

GraInger, J. (1989). How monolingual can a bilingual be: Interlexical interference in bilingual word recognition. Manuscript submitted for publication.

Grainger, J., \& Beauvillain, C. (1987). Language blocking and lexical 
access in bilinguals. Quarterly Journal of Experimental Psychology, 39A, 295-319.

GUNTHER, H., \& GREESE, B. (1985). Lexical hermits and the pronunciation of visually presented words. Forschungsberichte des Instituts für Phonetik und Sprachliche Kommunikation des Universität München, 21, 25-52.

Havens, L. L., \& Foote, W. E. (1963). The effect of competition on visual duration threshold and its independence of stimulus frequency. Journal of Experimental Psychology, 65, 6-11.

Holmes, V., \& O'Regan, J. K. (1987). Decomposing French words. In J. K. O'Regan \& A. Lévy-Schoen (Eds.), Eye movements: From physiology to cognition (pp. 459-466). Amsterdam: North-Holland.

Humphreys, G. W., EvetT, L. J., Quinlan, P. T., \& Besner, D. (1987). Orthographic priming: Qualitative differences between priming from identified and unidentified primes. In M. Coltheart (Ed.), $A t$ tention and performance XII: The psychology of reading (pp. 105125). New York: Erlbaum.

McClelland, J. L., \& Rumelhart, D. E. (1981). An interactive activation model of context effects in letter perception: Part 1. An account of basic findings. Psychological Review, 88, 375-405.

Morton, J. (1970). A functional model for memory. In D. A. Norman (Ed.), Models of human memory (pp. 203-254). New York: Academic Press.

NeELy, J. H. (1977). Semantic priming and retrieval from lexical memory: Roles of inhibitionless spreading activation and limited capacity attention. Journal of Experimental Psychology: General, 106, 226-254.

NorRIS, D. G. (1986). Word recognition: Context effects without priming. Cognition, 22, 93-136.
O'Regan, J. K., \& LévY-SChoen, A. (1987). Eye movement strategy and tactics in word recognition and reading. In M. Coltheart (Ed.), Attention and Performance XII: The psychology of reading (pp. 363383). New York: Erlbaum.

O'Regan, J. K., Lévy-SChoen, A., \& Jacobs, A. M. (1983). The effect of visibility on eye movement parameters in reading. Perception \& Psychophysics, 34, 121-138.

O'Regan, J. K., Pynte, J., Lévy-Schoen, A., Brugaillère, B. (1984). Convenient fixation location within isolated words of different length and structure. Journal of Experimental Psychology: Human Perception \& Performance, 10, 250-257.

Paap, K. R., Newsome, S. L., McDonald, J. E., \& Schvaneveldt, R. W. (1982). An activation-verification model for letter and word recognition: The word superiority effect. Psychological Review, 89, 573-594.

SAviN, H. B. (1963). Word frequency effects and errors in the perception of speech. Journal of the Acoustical Society of America, 35, 200-206.

SCheERER, E. (1987). Visual word recognition in German. In D. A. Allport, D. Mackay, W. Prinz, \& E. Scheerer (Eds.), Language perception and production: Shared mechanisms in listening, speaking, reading and writing (pp. 227-244). London: Academic Press.

TrÉsor de la Langue Française. (1971). Nancy, France: C.N.R.S.

(Manuscript received April 15, 1988; revision accepted for publication August 10, 1988.) 